\title{
Phytoplasma phylogenetics based on analysis of $\sec A$ and $23 S$ rRNA gene sequences for improved resolution of candidate species of 'Candidatus Phytoplasma'
}

\author{
Correspondence \\ Matthew Dickinson \\ matthew.dickinson@ \\ nottingham.ac.uk
}

\author{
Jennifer Hodgetts, ${ }^{1}$ Neil Boonham, ${ }^{2}$ Rick Mumford, ${ }^{2}$ Nigel Harrison ${ }^{3}$ \\ and Matthew Dickinson ${ }^{1}$
${ }^{1}$ School of Biosciences, University of Nottingham, Sutton Bonington Campus, Loughborough LE12 5RD, UK Avenue, Fort Lauderdale, FL 33314, USA \\ ${ }^{2}$ Central Science Laboratory, Sand Hutton, York YO41 1LZ, UK \\ ${ }^{3}$ University of Florida, Plant Pathology Department, Research and Education Center, 3205 College
}

\begin{abstract}
Phytoplasma phylogenetics has focused primarily on sequences of the non-coding 16S rRNA gene and the 16S-23S rRNA intergenic spacer region (16-23S ISR), and primers that enable amplification of these regions from all phytoplasmas by PCR are well established. In this study, primers based on the $\sec A$ gene have been developed into a semi-nested PCR assay that results in a sequence of the expected size (about $480 \mathrm{bp}$ ) from all 34 phytoplasmas examined, including strains representative of $1216 \mathrm{Sr}$ groups. Phylogenetic analysis of $\sec A$ gene sequences showed similar clustering of phytoplasmas when compared with clusters resolved by similar sequence analyses of a 16-23S ISR-23S rRNA gene contig or of the 16S rRNA gene alone. The main differences between trees were in the branch lengths, which were elongated in the 16-23S ISR-23S rRNA gene tree when compared with the 16S rRNA gene tree and elongated still further in the $\sec A$ gene tree, despite this being a shorter sequence. The improved resolution in the $\sec A$ gene-derived phylogenetic tree resulted in the $16 \mathrm{Srll}$ group splitting into two distinct clusters, while phytoplasmas associated with coconut lethal yellowing-type diseases split into three distinct groups, thereby supporting past proposals that they represent different candidate species within 'Candidatus Phytoplasma'. The ability to differentiate $16 \mathrm{Sr}$ groups and subgroups by virtual RFLP analysis of $\sec A$ gene sequences suggests that this gene may provide an informative alternative molecular marker for pathogen identification and diagnosis of phytoplasma diseases.
\end{abstract}

\section{INTRODUCTION}

Phytoplasmas are cell-wall-less bacteria that are currently unculturable in vitro. They are pathogens of insects and plants and are known to cause disease in hundreds of plant species worldwide (Liefting et al., 2004). Not all plant species infected with phytoplasmas develop disease symptoms, but infected plants normally show symptoms such as virescence, phyllody, yellowing, witches'-broom, leaf roll and generalized decline (Bertaccini et al., 2005). New disease reports are being published regularly, and the list of

Abbreviation: 16-23S ISR, 16S-23S rRNA intergenic spacer region.

The GenBank/EMBL/DDBJ accession numbers for the sequences determined in this study are detailed in Supplementary Table S1.

Accession numbers of sequences used in this study are detailed in a supplementary table available with the online version of this paper. hosts is growing and includes economically important food, fibre, forage, fruit and ornamental plants.

Phytoplasmas represent a distinct clade within the class Mollicutes, a branch of the Gram-positive eubacteria that lack cell walls. Other mollicutes include the mycoplasmas, acholeplasmas and spiroplasmas, and they are most closely related to bacteria such as Bacillus, Clostridium and Streptococcus. Phytoplasmas have small genomes ranging from 530 to $1350 \mathrm{~kb}$ (among the smallest known for any self-replicating organisms) and a low $\mathrm{G}+\mathrm{C}$ content in their DNA (23.0-29.5 mol\%), and were recently assigned to a novel candidate taxon, 'Candidatus Phytoplasma' (Lee et al., 2000; IRPCM Phytoplasma/Spiroplasma Working Team - Phytoplasma Taxonomy Group, 2004; Firrao et al., 2005). This category of Candidatus provides a means to name organisms such as phytoplasmas that cannot be 
Table 1. Phytoplasma strains employed

Isolates are listed according to their 16Sr rRNA gene RFLP group (16Sr) and the candidate species within 'Ca. Phytoplasma' to which they are related (Related Ca. species). Samples were provided as purified DNA or as infected Madagascar periwinkle or napier grass plants; sources are given as initials in the case of authors of the current study or surnames of individuals mentioned in the Acknowledgements.

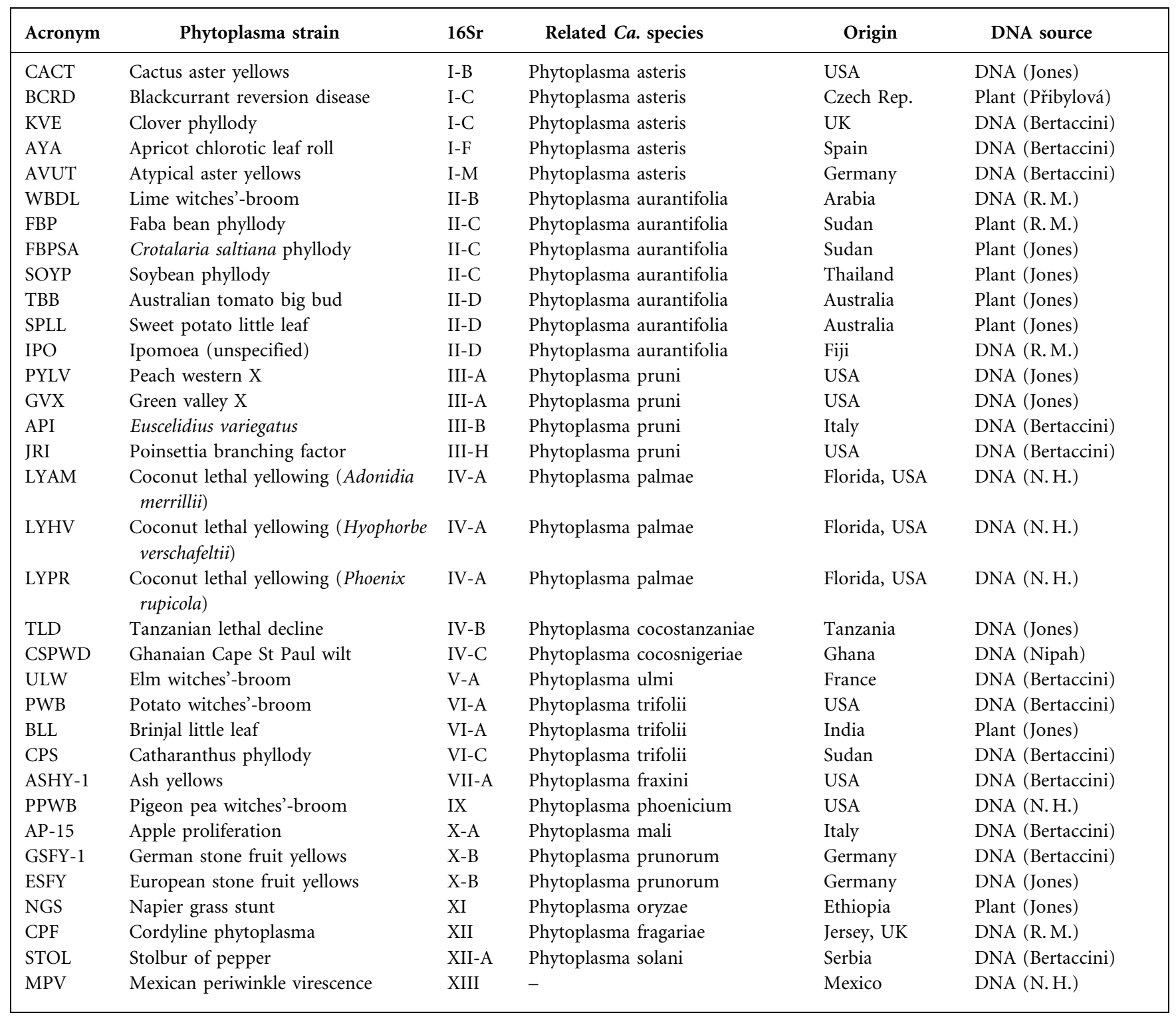

cultured in vitro, and over 25 major phylogenetic groups have been proposed within 'Candidatus Phytoplasma', delineated primarily on the basis that strains within a candidate species share at least $97.5 \%$ sequence identity within their 16S rRNA gene, with new branches being constantly identified (Montano et al., 2001; Schneider et al., 2005; Wei et al., 2007).

It has been recognized that there are deficiencies in basing a phylogenetic system for phytoplasmas solely on a single, highly conserved, non-coding gene such as the $16 \mathrm{~S}$ rRNA gene, especially for defining subgroups within a species (Streten \& Gibb, 2005). This has prompted the use of other, less well-conserved gene sequences to provide further insights into the phylogenetic relationships of phytoplasmas. The tuf gene, $r p$ (ribosomal protein) operon and 16S-23S rRNA intergenic spacer region (16-23S ISR) have been used to subdivide the 16SrI ('Ca. Phytoplasma asteris'-related) group (Marcone et al., 2000; Botti \& Bertaccini, 2003), along with the $\sec Y$ gene (Lee et al., 2006). The tuf gene and $r p$ operon have been used to subdivide the 16SrXII group (Streten \& Gibb, 2005). The $\sec Y$, map and $u v r B-\operatorname{deg} V$ genes have been similarly used to analyse strains in the $16 \mathrm{SrV}$ cluster (Arnaud et al., 2007). In addition, nusA (Shao et al., 2006), and other genes identified through the genome sequencing of aster yellows 


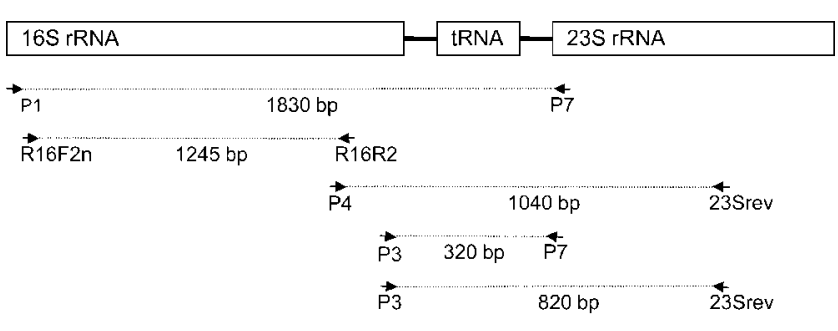

Fig. 1. Diagrammatic representation of the 16S-23S rRNA gene organization in phytoplasmas, showing the relative positions of the primers used in this study (indicated below the arrows) and the sizes of the products that they amplify (in base pairs) (not to scale).

witches'-broom (AYWB), such as PNPase, Ata (AAA type ATPase) and the cmp-binding factor (CBF) (Bai et al., 2004), have been used to support subdivisions within the aster yellows $16 \mathrm{SrI}$ group and to analyse their relationship with other bacteria.

It is important to note that these studies have largely examined the relationship between phytoplasmas within a specific $16 \mathrm{Sr}$ group, because the primers used for PCR are often group specific and do not amplify sequences from phytoplasmas in other groups. The only universal phytoplasma primers have been those based on the rRNA operon (Wang et al., 2003). Recently, however, Martini et al. (2007) have adapted $r p$ operon gene $r p l V(r p l 22)$ and $r p s C$ (rps3) primers so that they amplify these genes from a wide range of phytoplasmas and have used these sequences to construct a phylogenetic tree for 87 phytoplasma strains belonging to $1216 \mathrm{Sr}$ groups, which resulted in a finer resolution of lineages within the groups. In addition, these

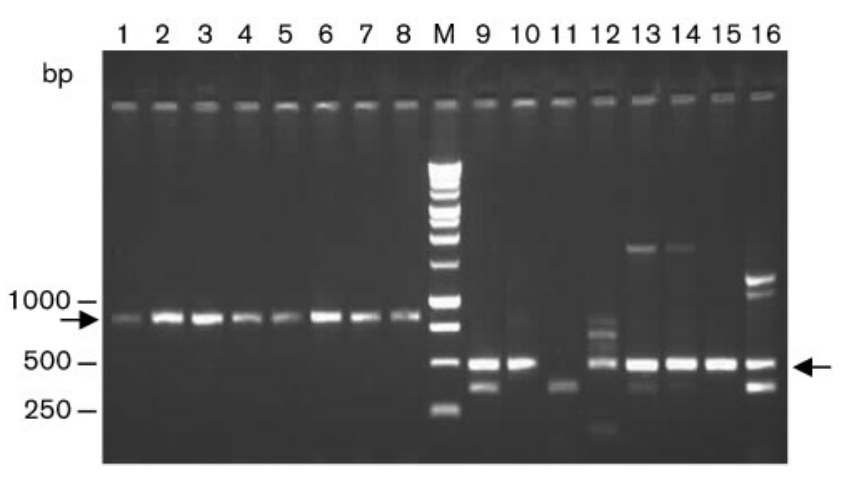

Fig. 2. $P C R$ products obtained using the $\sec A$ primers. Lanes 18 contain products obtained using primers SecAfor 1 and SecArev3 (840 bp) and lanes 9-16 contain the products obtained using a semi-nested PCR approach with primers SecAfor2 and SecArev3 (480 bp). Lanes: 1, SPLL; 2, KVE; 3, CPF; 4, GSFY-1; 5, AP-15; 6, API; 7, ULW; 8, GVX; 9, ULW; 10, NGS; 11, healthy napier grass control; 12, ASHY-1; 13, PWB; 14, CPS; 15, PYLV; 16, TBB. Lane M, $1 \mathrm{~kb}$ ladder. sequences were used to design group-specific primers for phytoplasma diagnostics.

In this study, we designed a new set of phytoplasma primers from the non-ribosomal $\sec A$ gene, which encodes SecA, the ATP-dependent force generator in the bacterial precursor protein translocation cascade system (Economou, 1999). Used in PCR, the primers amplified a $s e c A$ gene sequence (about $480 \mathrm{bp}$ ) from all phytoplasmas tested, including representatives from $1216 \mathrm{Sr}$ groups. This enabled us to make use of a less well-conserved gene as a phylogenetic parameter to produce an alternative phylogenetic analysis of the phytoplasmas.

\section{METHODS}

Phytoplasma strains and nucleic acid preparation. The phytoplasmas used in this study are listed in Table 1. They were either obtained as DNA preparations from other researchers or were maintained by us in Madagascar periwinkle (Catharanthus roseus), except for napier grass stunt, which was maintained in napier grass (Pennisetum purpureum), and Cape St Paul wilt, which was obtained from trunk borings of coconut (Cocos nucifera) palms in Ghana (Nipah et al., 2007). DNA was extracted from small quantities of plant tissue by the method of Doyle \& Doyle (1990).

Primer design, PCR, cloning and sequencing. Amplification of the 16S rRNA gene was performed by a nested PCR assay employing primers P1 (Deng \& Hiruki, 1991) and P7 (Smart et al., 1996) followed by primer pair R16F2n/R16R2 (Gundersen \& Lee, 1996) (Fig. 1). Both the 16-23S ISR and $23 \mathrm{~S}$ rRNA gene sequences were amplified by a semi-nested PCR assay using primers P4 (Smart et al., 1996) and 23Srev followed by primers P3 (Smart et al., 1996) and 23Srev and previously described conditions (Hodgetts et al., 2007). For the $\sec A$ gene, primers were designed by aligning $\sec A$ gene sequences using CLUSTAL W (Thompson et al., 1994) of 16SrI group phytoplasmas aster yellows witches'-broom (AYWB) (GenBank accession no. CP000061) and onion yellows (OY-M) (AP006628) with a $\sec A$ gene sequence derived from the coconut lethal yellowing (CLY) phytoplasma sequencing project, a 16SrIV-A subgroup strain (EU267187). Primer sequences were determined by visual assessment of the alignment, and three primers, SecAfor1 (5'-GARATGAAAACTGGRGAAGG-3'), SecAfor2 (5'-GAYGARGSWAGAACKCCT$\left.3^{\prime}\right)$ and SecArev3 (5'-GTTTTRGCAGTTCCTGTCATNCC-3'), were designed for use in a semi-nested PCR assay. PCR conditions for firstround PCR with primer pair SecAfor $1 / \operatorname{SecArev} 3$ were $94{ }^{\circ} \mathrm{C}$ for $2 \mathrm{~min}$ followed by 35 cycles of $94{ }^{\circ} \mathrm{C}$ for $30 \mathrm{~s}, 53{ }^{\circ} \mathrm{C}$ for $60 \mathrm{~s}$ and $72{ }^{\circ} \mathrm{C}$ for $90 \mathrm{~s}$ and a final extension step of $72{ }^{\circ} \mathrm{C}$ for $15 \mathrm{~min}$. Resulting PCR products were diluted 1:40 with sterile water and $1 \mu \mathrm{l}$ product was used in the semi-nested PCR using primer pair SecAfor $2 /$ SecArev3 as described above. PCR products were separated on $1.2 \%$ agarose gels in TBE ( $90 \mathrm{mM}$ Tris/borate/EDTA) buffer containing ethidium bromide and visualized under UV light. Semi-nested PCR products were cloned using the pGEM-T easy vector system (Promega) following the manufacturer's instructions. Clone inserts were amplified from transformant colonies by PCR using primers M13For and M13Rev. Cloned products were purified using a Qiaquick PCR Purification kit (Qiagen) before sequencing. Sequences were processed on both strands using Beckman Quickstart kit technology and WellRed Dye chemistry (infrared dyes) with a CEQ 8000 Genetic Analysis System (Beckman Coulter).

Phylogenetic analysis. BLAST searches (Altschul et al., 1990) were performed at the NCBI website (http://www.ncbi.nlm.nih.gov/). 


\begin{tabular}{|c|c|c|c|c|c|c|c|c|}
\hline & 1 & & & & & 51 & & \\
\hline AYWB & DEARTPLIIS & SVKETKNLY & KEAQRFVRTL & KNSHYLIELE & TKTIELTEEG & ITKAENFFQI & DNLYNIEHAS & LLHHVKNALK \\
\hline$B$ OY $-M$ & $\cdots \cdots$ & & & $\ldots R \ldots$. & & & - & -1 \\
\hline B AVUT & & & . . & . R. . & & & $\mathrm{Y}$ & \\
\hline В САCT & $\ldots \ldots \ldots$ & $\cdots \cdot$ & $\ldots$ & . R. & $\cdots$ & $\ldots$ & $\mathrm{v}$ & \\
\hline C KVE & .. & & & $\cdots$ & & .N. & & \\
\hline$C$ BCRD & $\ldots$ & & & & & .N. & & \\
\hline F AYA & $\ldots \ldots \ldots$ & I. & $\cdots$ & $\cdots \cdots$ & & $\ldots \ldots \ldots$ & & 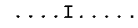 \\
\hline BBDL & $3 . .$. & NNT & RD.D. AKS. & D. & & . R . . L . K . & N. . & \\
\hline IC FBP & $\ldots G$ & $\mathrm{KF}$. & RD.D.AKS. & .SE. & & .R. . L . K & N... & \\
\hline IIC FBPSA & $\cdots$ & $\mathrm{KF}$. & . .AKS. & . SE...D. & .D. . & .R. . L . K & N. . & \\
\hline IC SOYP & $\cdots$ & $\mathbf{N}$ & is. & D. . & & .R. . L . K K & N.. & \\
\hline ID SPLL & & & is. & & s.. & .R. . & N. . & \\
\hline IID TBB & & & KS. & D. . & & R. . L . K . & & \\
\hline ID IPO & $\ldots \mathrm{G}$ & & KS, & D. & & .R. . L . K & & \\
\hline IIA PYLV & . & F. & . KS. & D. . & & VR . .A. . I & т... & ..s.. \\
\hline IIA GVX & & & ...KS. & & & A...L & T... & .5. \\
\hline IIB API & & & . & & & $\mathrm{V}$ & & s.. \\
\hline IIH JRI & & F. & . . KS & D. . & & VR ...A. . I & T... & ..s. \\
\hline IA LYAM & $\cdots$ & & $\ldots \mathrm{KK}$ & ..D. & ..s. & 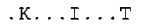 & KD. . & $\ldots$ \\
\hline IVA LYHV & & & . . KK. & & $\ldots s$ & & KD. . . & \\
\hline VA LYPR & & & . KK. & . &.$S$. & 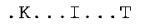 & $\mathrm{KD}$. . & \\
\hline VB TLD & $\ldots \mathrm{G}$ & & . AK. & o. & & .K...I...M & iI & 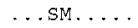 \\
\hline IC CSPWD & $\ldots \mathrm{G}$ & & $\ldots \mathrm{KN}$ & A. & $\mathrm{s}$ & .K. . . L . HM & N...s & . \\
\hline ULW & & & & & & & & \\
\hline IA PWB & . G. & $F$. & $\ldots k \ldots$ & o. . & & .K...T. & $\mathrm{K}$. & 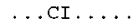 \\
\hline IA BLL & & $F$. & $\ldots \kappa \ldots$ & D. . & & . К. . Т. & к.. & . . CI.H. \\
\hline IC CPS & $\ldots G$ & & & & & & & \\
\hline IIA ASH & & & & & $\mathrm{K}$. & & & \\
\hline IX PFWB & & F. & T..... & .E...I.D. & s.s. & .Q.G.K...M & T...S & . I. \\
\hline XA AP15 & & & $\ldots \ldots$ & $\mathrm{TD}$ & $\ldots \mathrm{K}$ & & . P & \\
\hline 3 GSFY & & & & & . K. & & & \\
\hline$X B$ ESFY & & & & 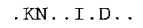 & . K. & & & \\
\hline XI NGS & $\ldots G \ldots$ & DYA. KGQKF . & MD.N. . AKI . & .TH . .I.D. . & $\mathrm{N}$ & .K.G.S..R. & S.F. . SNNIIV & $\ldots$ CI. \\
\hline I $\quad \mathrm{CP}$ & & & . AK. . & . TQ. & S.. &. $\mathrm{N}$ & D.Q.S. & \\
\hline & & & & & & & & \\
\hline
\end{tabular}

101

151

\begin{tabular}{|c|c|c|c|c|c|c|c|c|}
\hline & & & & & & & & \\
\hline IA $A Y W B$ & AAFTMHKDKD & YLVDYKDGQV & LIIDQFTGRA & LPGRQFSDGL & HQALEAKEGL & LIKKETSIGA & TITYQNFFRL & YQKLSGMTGT \\
\hline$B$ OY $-M$ & & & & & & $\ldots \mathrm{E}$ & & . $\mathrm{H}$ \\
\hline B AVUT & & & & & $\ldots \mathrm{V}$ & $\ldots E$ & & . HE \\
\hline IB CACT & $\ldots \ldots \ldots \mathrm{N}$. & & & & $\ldots \mathrm{V}$ & $\ldots E$. & &. $\mathrm{H}$ \\
\hline C KVE & $\ldots \ldots \ldots$ & $\ldots \ldots \ldots$ & $\ldots \ldots v$ & $\ldots \ldots \ldots$ & $\ldots \ldots$ v & $\ldots \mathrm{E}$ & & .H. \\
\hline BCRD & $\cdots$ & $\cdots$ & $\ldots \ldots v v$ & $\cdots \cdots$ & $\ldots \ldots v v$ & . E. & & . H. \\
\hline F AYA & & & & & $\ldots \mathrm{V}$ & $\ldots \mathrm{E}$ & & \\
\hline IB WBDL & .C.I.E... & $\ldots$ OND-NI & $\ldots$ &.$I$ & $\ldots \ldots \ldots$ NC & ... A. . $\Xi T S$ & . L..N & . KLI \\
\hline IC FBP & .c. & $D--N I$ & V...P. & & $\ldots \ldots$ NC & ..A. . $\Xi \mathrm{TS}$ & $M \ldots \ldots L \ldots N$ & . KLI \\
\hline IC FBPSA & .c. & $--N I$ & V...P. & $\ldots$ & $\ldots \mathrm{NC}$ & . .A. ETS. & M. . . L L . N & \\
\hline IC SOYP & C.I.E. . & $\mathrm{JD}--\mathrm{NI}$ & v..P. . . & $\ldots$ & . NC & ...A. ETS. & M. . LL LN & . KLI \\
\hline ID SPLL & R. . & $I-\ldots I$ & $\ldots \ldots$ & $\ldots \ldots$ & $\ldots \ldots \ldots \mathrm{NC}$ & I..A. ETS. & $\ldots \ldots L \ldots N$ &. $\mathrm{~F}$ \\
\hline IID TBB & . C & - . I & v & .I &. $\mathrm{NC}$ & M. .A. ETS. & . L. .N & \\
\hline IID IPO &. $\mathrm{C}$ & {$[-. . I$} & &.$I$ &. $\mathrm{NC}$ & I. .A. ETS. & M....L. .N &. $\mathrm{K}$ \\
\hline IIIA PYLV &.$G$ & $--\ldots$ & I & $\cdots$ & $\ldots \mathrm{I}$ & V. E. EVS. & $\ldots \ldots \ldots I$ & $\mathrm{R}$ \\
\hline IIA GVX &. $\mathrm{G}$ & $\cdots$ & $\ldots \ldots \ldots \mathrm{I}$ & & $\ldots$ I $\ldots$ C & V..E. . & $\ldots I$ & \\
\hline IIB API &. $\mathrm{V}$ & $-\ldots$ &.$I$ & & $\ldots I$ & V..E..EVS. & & $\cdot R$ \\
\hline IIH JRI & & $-\ldots$ & $\ldots \ldots$ & & $\ldots I$ & V..E. E & & \\
\hline VA LYAM &. $\mathrm{Y}$ & $-\mathrm{K}$. & $\ldots$. $\ldots$ I & ..E. & $\ldots$....c & TV.E. & $\ldots I$ & . K. \\
\hline VA LYHV &. $\mathrm{Y}$ & $-K$ & $\ldots 1$ & . E. . & $\ldots c$ & s. & $\ldots I$ & $\mathrm{~K}$. \\
\hline IVA LYPR & & $-\mathrm{K}$. & $\ldots \mathrm{I}$ & .E. & $\ldots$ & TV &.$I$ & . K. \\
\hline VB TLD & &.$- D$ & $\ldots L$ & .H...... I & s... & SS & & $\mathrm{K}$ \\
\hline IVC CSPWD &. $\mathrm{Y}$ & $-E$ & $\ldots V_{1}$ &.$G \ldots$ & $\ldots \mathrm{C}$ & T. .E. EVS. & $\ldots I$ &. $\mathrm{~K}$. \\
\hline VA ULW & .V.I & $\ldots$ NN- $-\mathrm{K}$ & $\ldots \ldots \ldots v$ &. $\mathrm{Q}$ & $\ldots$ & S.EG. E.N. & $\ldots \ldots \ldots$ & . K. I \\
\hline IA PWB &. $\mathrm{F}$ & & & & & N.EP.E.S. & & .K.I \\
\hline IA BLL &. $\mathrm{F}$ & & & &. $\mathrm{C}$ & . E.s. & & .K.I \\
\hline IC CPS & . F & $-\mathrm{KI}$ & $\ldots I$ & & $\ldots \mathrm{C}$ & D.EP.E.S. & $\ldots I$ & .K.I. \\
\hline IIA ASHY & .C.L & $--R I$ & $\ldots \mathrm{V}$ & & $\ldots \mathrm{C}$ & H.EA..E.S. & $\ldots I$ &. $\mathrm{~K}$. \\
\hline$X \quad$ PPWB & . $\mathrm{H}$ & & & & & .AE.S. & & $\mathrm{K}$ \\
\hline $\mathrm{XA}$ AP15 & . F &.$- \mathrm{I}$ &. $\mathrm{I}$ & N. & . RV & T..P.T.S. & & .K. I \\
\hline $\mathrm{XB}$ GSFY & .F.I. . NH. . & $\ldots \mathrm{vK}$ & $\ldots \Xi \ldots I$ & .N. & . . RV & T.EP_.N.S. & & .K.I. \\
\hline$B$ ESFY & .F. & &. $\mathrm{I}$ & &. $\mathrm{RV}$ & T.EP..N.S. & & . K.I \\
\hline I NGS &. $\mathrm{H}$ & $--N I$ & & 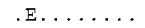 & & I . E. E.A. & & . K. I \\
\hline XII CPF & .v. & $\ldots \mathrm{QN}--$ &. $\mathrm{V}$ & & & . E E. & &. $\mathrm{H}$ \\
\hline IIA STOI & . F. & 0. &.. $\mathrm{v}$ & & & 5. & & \\
\hline III MPV & .N. & $\ldots \mathrm{ON}-\ldots$ & $\ldots \ldots \ldots v$ & & & $\ldots$ E. . . & & \\
\hline
\end{tabular}

Fig. 3. Alignment of translated $\sec A$ sequences between the annealing positions of primers SecAfor2 and SecArev3 for the phytoplasmas used in this study along with aster yellows witches'-broom (AYWB) (GenBank accession no. CP000061) and onion yellows (OY-M) (AP006628). Sequences were aligned using CLUSTAL W (Thompson et al., 1994), and dots represent amino acids identical to the AYWB consensus sequence; two dashes represent a 2 aa deletion in the non-16Srl sequences.

Phylogenetic trees were constructed from secA, 16S rRNA gene and 16-23S ISR-23S rRNA gene sequences. Sequence alignments were performed using CLUSTAL W (Thompson et al., 1994). Phylogenetic and molecular evolutionary analyses were performed with MEGA version 3.1 software (Kumar et al., 2004) using the neighbour-joining method with default values and 1000 replications for bootstrap analysis. In silico restriction enzyme digests and virtual gel plotting was performed using the pDRAW32 program developed by AcaClone Software (http://www.acaclone.com) as described by Wei et al. (2007). 
(a)

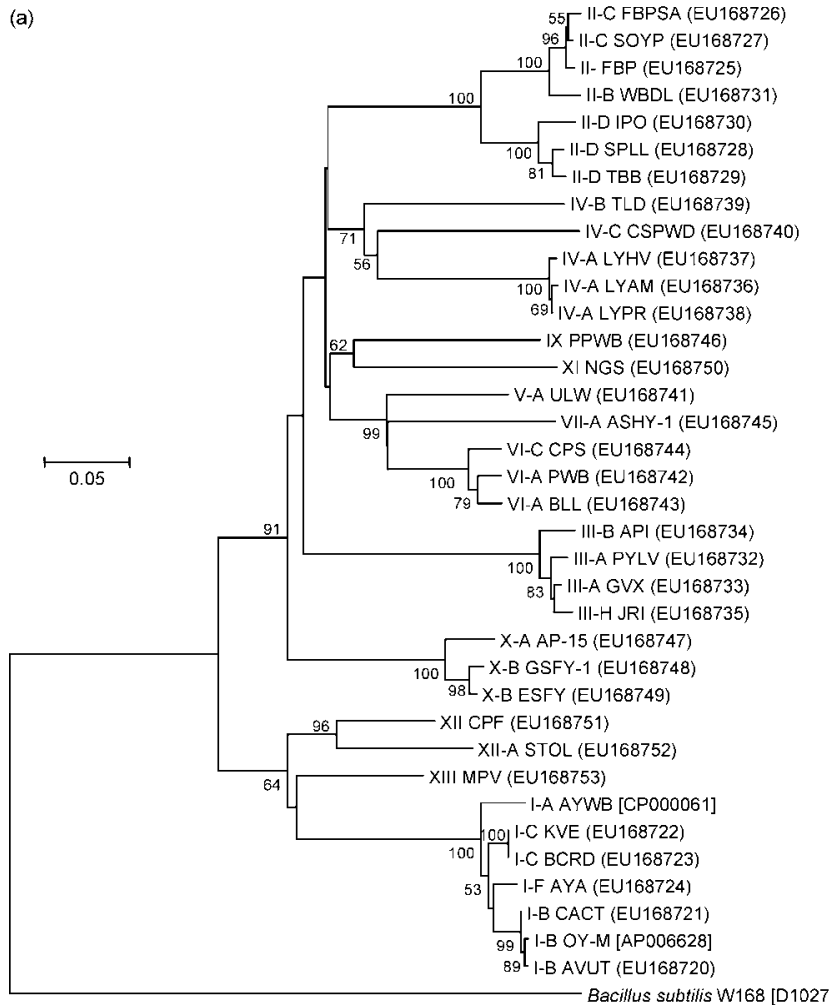

(c)

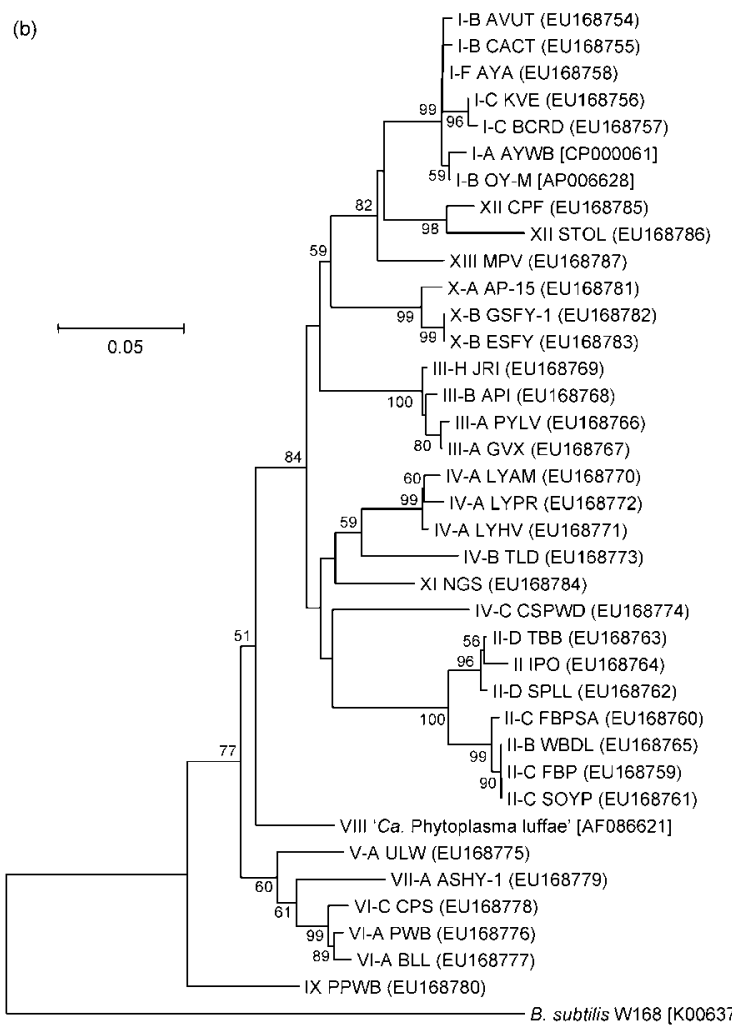

(d)

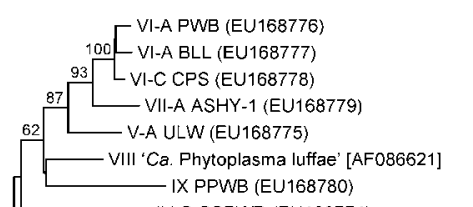

0.05 IV-C CSPWD (EU168774) IV-B TLD (EU168773) 89 IV-A LYAM (EU168770) 100 IV-A LYHV (EU168771) 79L IV-A LYPR (EU168772) XI NGS (EU168784) —III-B API (EU168768) $100[$ III-H JRI (EU168769) 68 III-A PYLV (EU168766) ${ }_{88}^{68}$ III-A GVX (EU168767) 60 II-D TBB (EU168763) $99-11$ IPO (EU168764) II-D SPLL (EU168762)

100 II-C FBPSA (EU168760) 100 II-C FBP (EU168759) 96 - II-C SOYP (EU168761) 51 II-B WBDL (EU168765) ${ }_{100}^{X-B}$ GSFY-1 (EU168782)

100 X-B ESFY (EU 168783) LX-A AP-15 (EU168781) 99 X-B GSFY-1 (EU168782)

99 X-B ESFY (EU168783)

X-A AP-15 (EU168781)

XIII MPV (EU168787)

XII STOL (EU168786)

XII CPF (EU168785)

C BCRD (EU168757)

B AVUT (EU168754)

I-A AYWB [CP000061]

I-B CACT (EU168755)

I-B OY-M [AP006628]

I-F AYA (EU168758)

LI-C KVE (EU168756)

Bacillus subtilis W168 [K00637]
$80 \quad \begin{gathered}99-X I I \text { CPF (EU168785) } \\ \text { XII STOL (EU168786) }\end{gathered}$

- XIII MPV (EU168787)

I-A AYWB [CP000061]

I-B OY-M [AP006628]

I-C KVE (EU168756)

I-C BCRD (EU168757)

I-B CACT (EU168755)

52 I-B AVUT (EU168754)

I-F AYA (EU168758) 


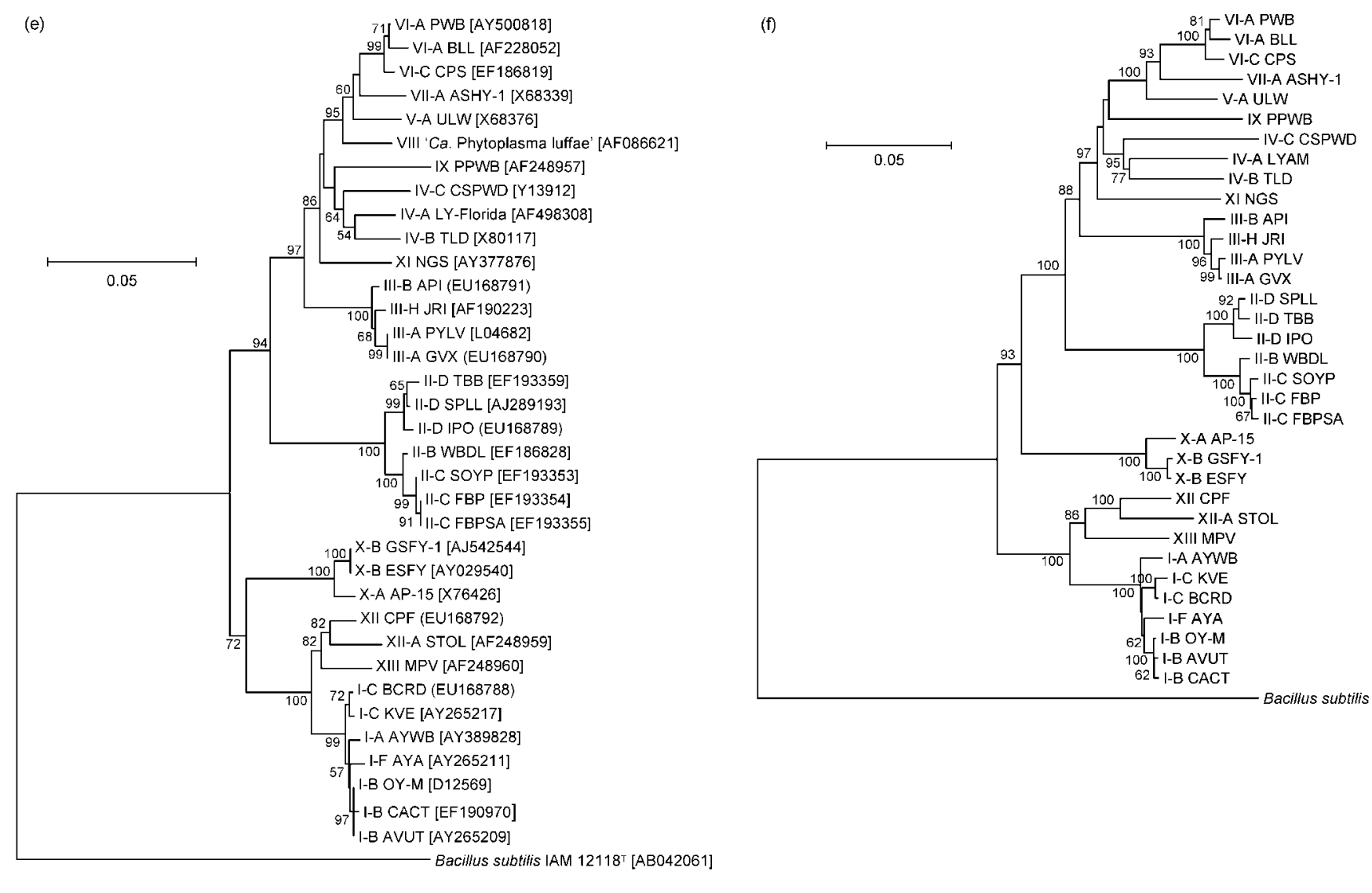

Fig. 4. Dendrograms, constructed by the neighbour-joining method, showing the phylogenetic relationships amongst all the phytoplasmas listed in Table 1 along with AYWB, OY-M and Bacillus subtilis strains based on DNA sequences of the secA gene (between primers SecAfor2 and SecArev3) (a), the 23S rRNA gene (between primers P7 and 23Srev) (b), the 16-23S ISR (between primers P3 and P7) (c), the 16-23S ISR plus 500 bp of the 23S rRNA gene (between primers P3 and 23Srev) (d), the 16S rRNA gene (between primers R16F2n and R16R2) (e) and secA plus 16S rRNA plus spacer plus 23S RNA genes combined into a single contiguous sequence ( $f$ ). GenBank accession numbers for sequences obtained as part of this project are shown in parentheses, whilst those for previously published sequences are shown in square brackets; accession numbers are detailed in Supplementary Table S1. Bootstrap values greater than $50 \%$ (expressed as percentages of 1000 replications) are shown, and branch lengths are proportional to the number of inferred character state transformations. Bars, 0.05 ( $a, b, d, e$, f) and 0.1 (c) substitutions per nucleotide position.

\section{RESULTS AND DISCUSSION}

\section{Primer design for the secA gene}

Prior to this study, the phytoplasma $\sec A$ gene sequences available for primer design in the NCBI nucleotide database were limited to full-length sequences from 16SrI group strains AYWB and OY-M and partial gene sequences from 16SrII group strain Australian tomato big bud (GenBank accession no. AF494511) and 16SrXI strain sugar cane grassy shoot (AM261835). To amplify the entire secA gene from other phytoplasmas would require knowledge of flanking sequences for primer design. Whilst these sequences are known and are identical for AYWB and OY-M, they remain unknown for other phytoplasmas. However, recent studies have demonstrated that gene orders and synteny vary between phytoplasmas
(Jomantiene et al., 2007), including closely related strains such as AYWB and OY-M (Bai et al., 2006). Thus, it seemed unlikely that primers derived from sequences flanking the secA gene would succeed in amplifying the complete gene from diverse groups of phytoplasmas. Instead regions within the gene that were most conserved between 16SrI group phytoplasmas and the phylogenetically more distant CLY phytoplasma (16SrIV-A) were exploited for primer design in an attempt to amplify $\sec A$ gene sequences from most or all phytoplasmas.

From a multiple sequence alignment, three conserved regions within the $\sec A$ gene, corresponding to nucleotide positions $296-315,650-668$ and $1115-1138$ in the $16 \mathrm{SrI}$ phytoplasma genes, were identified and used in the design of primers SecAfor1, SecAfor2 and SecArev3, respectively. Primer pair SecAfor1/SecArev3 used in PCR generated 
products of the expected size (about $840 \mathrm{bp}$ ) from approximately $90 \%$ of the phytoplasma DNA samples tested although, for some phytoplasmas, amplifications were weak, reflecting a low titre of phytoplasma DNA in these samples or, possibly, poor primer binding (Fig. 2). No products were amplified from uninfected plant controls. Similarly, use of primer pair SecAfor2/SecArev3 also resulted in amplification of a product of the expected size (approx. $480 \mathrm{bp}$ ) from $90 \%$ of the phytoplasma isolates. While there was overlap between these phytoplasmas and those successfully amplified with SecAfor 1/ SecArev3, they were not all the same. Primer pair SecAfor2/SecArev3 amplified additional PCR products of different sizes from a small number of DNA samples, including uninfected plant controls; however, the predicted 480 bp product was amplified exclusively from phytoplasma DNA samples. When a semi-nested approach was used in which phytoplasma DNA samples were first amplified with SecAfor $1 /$ SecArev3 and then reamplified with SecAfor2/SecArev3, the expected PCR product (approx. $480 \mathrm{bp)}$ ) was readily obtained from all phytoplasmas. Once again, additional non-target DNA products were occasionally present in some samples, including uninfected plant controls (Fig. 2).

\section{Cloning and sequencing of phytoplasma DNA}

$\sec A$ gene products were amplified, cloned and sequenced from all 34 phytoplasmas examined in this study (see Table 1). These included strains belonging to 12 of the $16 \mathrm{Sr}$ groups proposed by Lee et al. (1993, 2000). Although amplified secA gene sequences were found to vary in length (482 or $488 \mathrm{bp}$ ), alignment of the translated sequences (Fig. 3) confirmed that they all encoded the same region of the SecA protein. Additional larger or smaller PCR products amplified occasionally along with $s e c A$ sequences were also cloned and sequenced. BLAST analysis of the resulting sequences determined that none were of phytoplasma origin. Instead, they consisted of unrelated bacterial or plant sequences amplified by the degenerate primers.

Both 16S rRNA and 16-23S ISR-23S rRNA operon sequences were readily amplified by nested or semi-nested PCRs. Cloning and sequencing of products was used to ascertain or confirm phytoplasma identity, since comparable sequences for most of the phytoplasmas used in this study were available in the NCBI database. These efforts also provided new sequence data including contiguous 1623S ISR plus $450 \mathrm{bp}$ of $23 \mathrm{~S}$ rRNA gene sequences for 34 strains, as well as 16S rRNA gene sequences for five phytoplasmas (see Supplementary Table S1 available in IJSEM Online for GenBank accession numbers of all sequences used in this study).

\section{Phylogenetic analysis}

The following sequences obtained during this study were subjected to phylogenetic analysis as follows: the $\sec A$ gene between primers SecAfor2 and SecArev3 (Fig. 4a), the 23S rRNA gene between primers P7 and 23Srev (Fig. 4b), the 16-23S ISR between primers P3 and P7 (Fig. 4c), the 16$23 \mathrm{~S}$ ISR and contiguous $23 \mathrm{~S}$ rRNA gene sequence between P3 and 23Srev (Fig. 4d), the 16S rRNA gene between primers R16F2n and R16R2 (Fig. 4e) and the 16S rRNA, 16-23S ISR, 23S rRNA and secA gene sequences combined into a hypothetical contiguous sequence (Fig. 4f).

The trees derived from these analyses show remarkable similarity in their clustering and strong support for phytoplasma groupings through bootstrap analysis, with the exception of the trees derived from the $23 \mathrm{~S}$ rRNA gene alone and the 16-23S ISR alone (Fig. 4b, c). These latter two trees are based on relatively short sequences. The 1623S ISR sequences in particular are highly variable, and the tree is poorly supported by bootstrap analysis. The main anomalies associated with the 16-23S ISR tree are the positioning of clover phyllody (KVE) in a distinct lineage apart from that of other 16SrI strains and the positioning of pigeon pea witches'-broom (PPWB), a group 16SrIX phytoplasma, within group 16SrIV, consisting of CLY phytoplasma and related strains. There have been previous reports of anomalies within the 16S-23S ISR. For example, De La Rue et al. (2001) reported that one of the two rRNA operons of stylosanthes little leaf phytoplasma lacks a tRNA ${ }^{\text {Ile }}$ gene in the 16S-23S ISR. The tRNA ${ }^{\text {lle }}$ gene is intact and well conserved in all the sequences that we report in this paper, but there are a large number of base substitutions and variations in sequence length in the regions between the 16S rRNA and tRNA ${ }^{\text {Ile }}$ genes and between the tRNA ${ }^{\text {Ile }}$ and $23 \mathrm{~S}$ rRNA genes. This probably reflects the fact that these intergenic regions are under few or no evolutionary constraints and are thus highly variable both within and between phytoplasma phylogenetic groups.

The tree based on the 23S rRNA gene sequences alone (Fig. 4b) also contains anomalies and places 16SrIX PPWB in a distinct group and places 16SrXI napier grass stunt closer to CLY (16SrIV-A) and Tanzanian lethal decline (16SrIV-B) than Cape St. Paul wilt (16SrIV-C). These anomalies are seemingly resolved in all of the other trees based on longer sequences, and the main differences between these other phylograms are the branch lengths, which are elongated in the 16-23S ISR plus 23S rRNA gene tree (Fig. 4d) compared with the $16 \mathrm{~S}$ rRNA gene tree (Fig. 4e) and elongated still further in the $\sec A$ gene tree (Fig. 4a), despite the use of the shorter $\sec A$ gene sequence. The tree that combines all sequences into a single hypothetical consensus sequence (Fig. 4f) provides particularly good resolution of the phylogenetic groups and very strong bootstrap support for these groups. This grouping of strains is consistent with those reported in previous studies based on the $16 \mathrm{~S}$ rRNA gene (Firrao et al., 2005; Wei et al., 2007), the $16 \mathrm{~S}$ rRNA gene plus 16S-23S ISR (Wang et al., 2003) and the $r p$ genes (Martini et al., 2007). Groups 16SrI and 16SrXII form into a distinct subclade, referred to as the AS branch by Wang et al. (2003), and our study confirms the findings of Martini et al. 
Table 2. Predicted sizes for $\sec A$ gene fragments following digestion with $T a q l, M b o l$ or $A / u l$

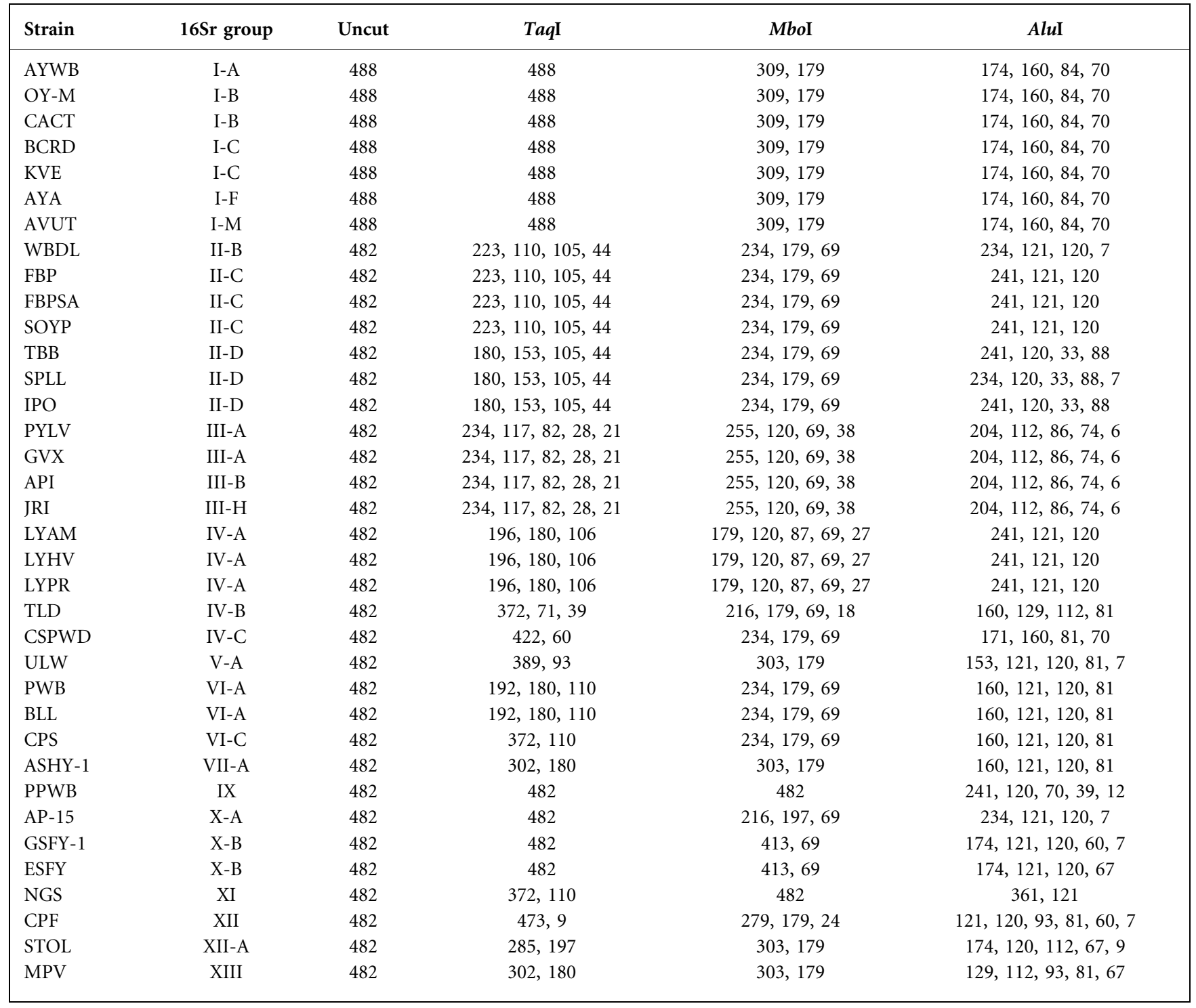

(2007) and Wei et al. (2007) that place Mexican periwinkle virescence phytoplasma (16SrXIII) into this subclade (an isolate that was not used in the original study; Wang et al., 2003). Within the AS branch, the secA gene analysis is also able to separate the I-A, I-B, I-C and I-F subgroups of $16 \mathrm{SrI}$, which is in line with previous analyses based on the sec $Y$ gene (Lee et al., 2006) and the tuf and $r p$ genes (Marcone et al., 2000; Botti \& Bertaccini, 2003). The secA gene analysis also shows distinct separation between the two 16SrXII strains used, stolbur (which is classified as ' $\mathrm{Ca}$. Phytoplasma solani'-related) and an isolate from cordyline from Jersey (classified as ' $\mathrm{Ca}$. Phytoplasma fragariae'-related based on $16 \mathrm{~S}$ rRNA gene analysis), and supports the separation of this $16 \mathrm{Sr}$ group into distinct candidate species.

Most of the remaining phytoplasmas and 16Sr groups are on a separate branch of the tree, referred to as the WB branch (Wang et al., 2003), and phytoplasmas in this branch are believed to have evolved independently from the AS branch and to possess smaller genomes. The 16SrX apple proliferation group, however, forms a distinct subgroup of its own, and there is an ambiguity between our 16S rRNA gene and 16S-23S ISR plus 23S rRNA gene trees, which place these phytoplasmas closer to the AS branch, and the secA gene tree, which places them closer to the WB branch. This anomaly is consistent with the findings of Martini et al. (2007), who also found that the 16SrX group was in slightly different positions in trees, depending whether these trees were based on $16 \mathrm{~S}$ rRNA gene sequences or $r p$ gene sequences. The tree in which all our data have been combined (Fig. 4f) places the $16 \mathrm{SrX}$ group into a distinct cluster between the AS and WB branches of the tree, consistent with the phylogenetic analyses of Wei et al. (2007).

The secA gene tree (Fig. 4a) also indicates a clear split within the 16SrII group, currently classified as ' $\mathrm{Ca}$. Phytoplasma 

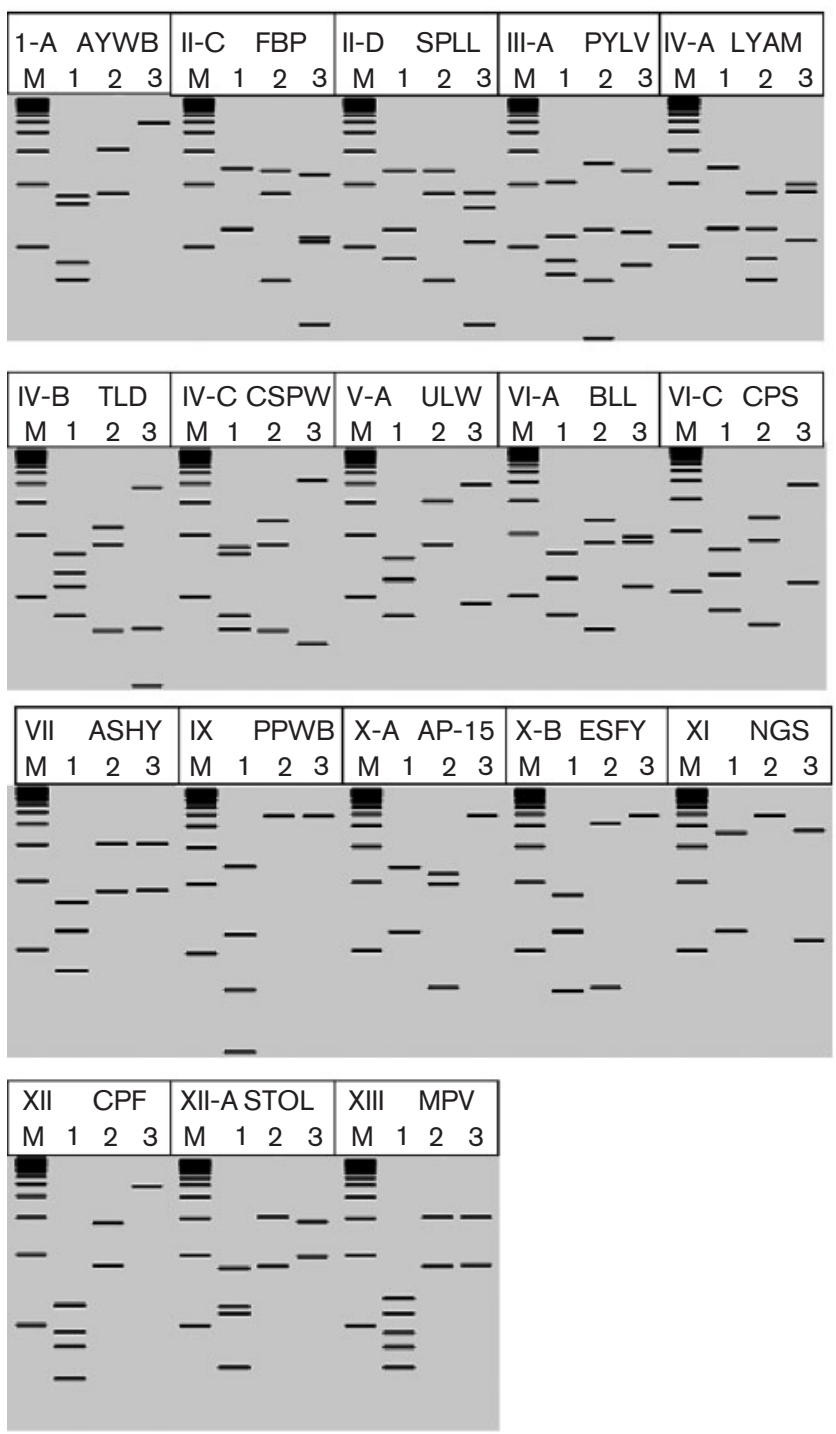

Fig. 5. Computer-simulated virtual gel analysis of $\sec A$ gene PCR products produced using primers SecAfor2 and SecArev3, following digestion with Alul (lanes 1), Mbol (2) and Taql (3). Lanes M, Promega 100 bp step ladder.

aurantifolia' and related strains. The 16SrII-B and 16SrII-C strains cluster separately from 16SrII-D strains, and the level of diversity between these two clusters is as great as that which occurs between separate candidate species of ' $\mathrm{Ca}$. Phytoplasma' such as apple proliferation ('Ca. Phytoplasma mali') and stone fruit yellows ('Ca. Phytoplasma prunorum'). Wei et al. (2007) have recently classified the 16SrII-B strains alone as ' $\mathrm{Ca}$. Phytoplasma aurantifolia' whilst classifying the 16SrII-D strains at ' $\mathrm{Ca}$. Phytoplasma australasiae'. Our results support this subdivision of the 16SrII group into at least two candidate species, and suggest that the 16SrII-C strains should be included with the 16SrII-B strains as ' $\mathrm{Ca}$. Phytoplasma aurantifolia'.
The 16SrIV group also shows clear distinction between strains within the group. These are phytoplasmas that cause economically important lethal diseases of coconuts, all characterized by similar syndromes that include premature fruit drop, floral necrosis, leaf discoloration and decline. Subgroup 16SrIV-A phytoplasmas are associated with lethal yellowing (LY) of coconut and other palm species in the Americas (Harrison et al., 2002), whereas phytoplasmas that induce symptoms similar to LY on coconut in Africa are referred to by other names to reflect strain differences that have previously been identified through $16 \mathrm{~S}$ rRNA gene analysis. Furthermore, Mpunami et al. (1999) also showed that it was possible to differentiate East African from West African coconut-associated phytoplasmas by selective amplification of $16 \mathrm{~S}$ rRNA gene sequences during PCR or by RFLP analysis of 16S rRNA genes and, in the recent report by Wei et al. (2007), the Nigerian coconut lethal decline group (LDN) has been allocated a distinct 16Sr group, 16SrXXII-A. Our analysis of the secA gene clearly supports a high degree of divergence between the different coconut phytoplasmas and supports their separation into at least three distinct candidate species that reflect the geographical origins of the strains.

\section{Can the secA gene be utilized for phytoplasma diagnostics?}

Because phytoplasmas cannot be cultured in cell-free media, the most widely used diagnostic test for them, and for strain identification, involves PCR amplification of the 16S rRNA gene followed by restriction enzyme digestion of the PCR products with enzymes such as AluI, HaeIII or RsaI. This results in characteristic RFLP patterns for different strains, which can be resolved by agarose or acrylamide gel electrophoresis (Lee et al., 2002). However, this method does not provide clear resolution of all the 16Sr groups and usually does not resolve subgroups clearly without the use of a wide range of restriction endonucleases (Wei et al., 2007), so other methods have been developed. These include heteroduplex mobility assays based on the 16-23S ISR, which have been used to differentiate 16SrI subgroups (Wang \& Hiruki, 2005), and terminal restriction fragment length polymorphisms (TRFLP) based on the 23S rRNA gene, which distinguish the various 16Sr groups (Hodgetts et al., 2007).

The secA gene sequences amplified by semi-nested PCR in this work offer an additional approach to phytoplasma diagnostics and strain identification. Firstly, all phytoplasmas tested so far from a wide range of taxonomic groups gave distinct PCR products of 482 or $488 \mathrm{bp}$. These included DNA sources in which the titre of phytoplasma DNA was low and for which a nested approach was also required for successful $16 \mathrm{~S}$ rRNA gene amplification (results not shown). This is despite the fact that the $\sec A$ gene is a single-copy gene in the phytoplasma genome, whilst the rRNA operon is present in two copies. The secA PCR product was readily distinguishable from other bands 
Table 3. Predicted sizes for 16-23S ISR plus $23 S$ gene fragments following digestion with Taql, Mbol or Alul

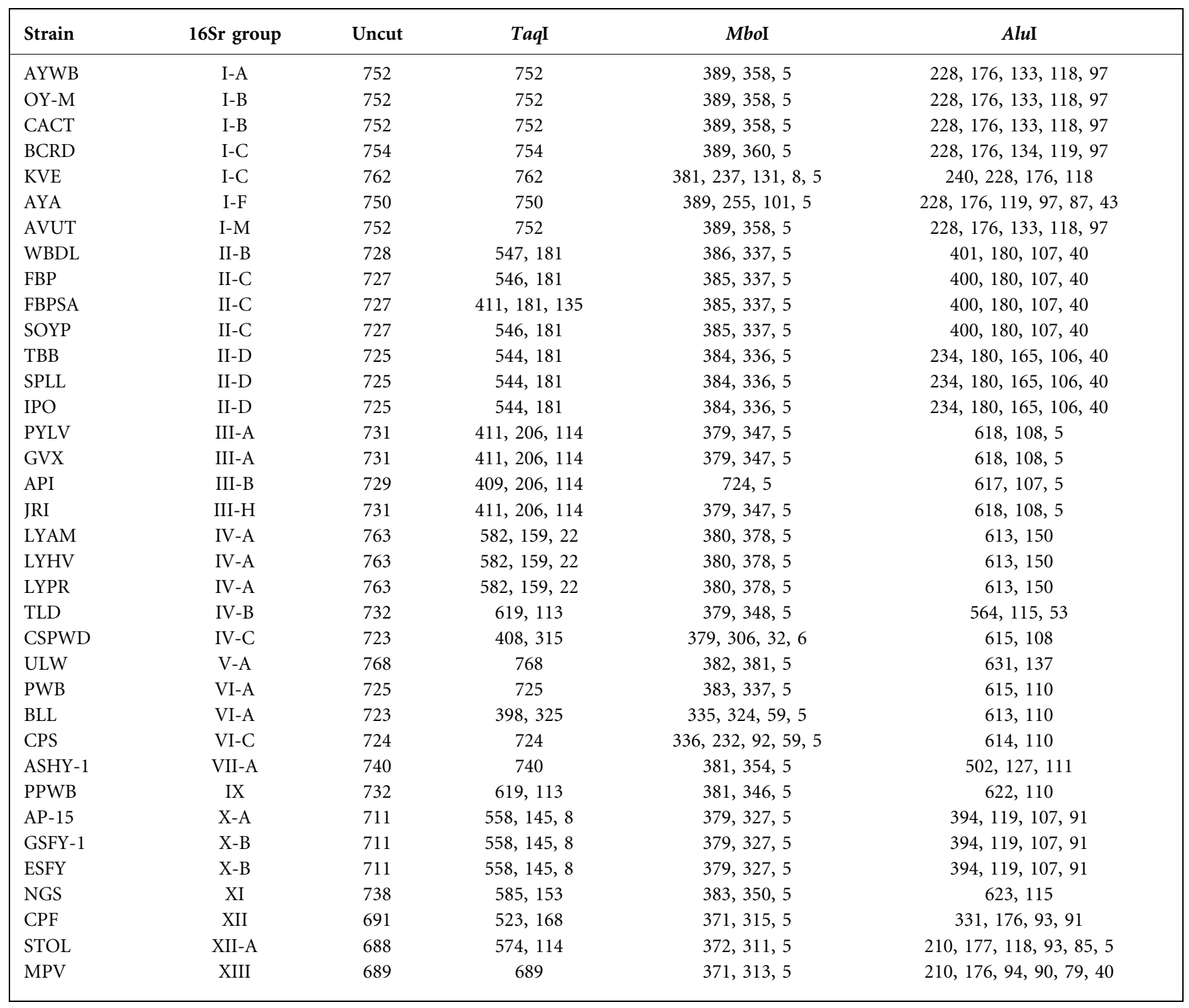

that were occasionally amplified by the primers. Secondly, the 482 or 488 bp SecAfor2/SecArev3-primed sequences were analysed in silico to determine sizes of restriction fragments generated by several key enzymes (Table 2), and computer-simulated virtual gels were derived from this analysis by the method of Wei et al. (2007) (Fig. 5). It was predicted from this analysis that digestion of $\sec A$ with TaqI should produce well-defined RFLP patterns that differentiate most $16 \mathrm{Sr}$ groups and some subgroups, such as those within $16 \mathrm{SrII}, 16 \mathrm{SrIV}$ and $16 \mathrm{SrX}$. Groups and subgroups not resolved by TaqI could be resolved by digestion with $M b o I$. The only exceptions were groups 16 SrVII and 16SrXIII, which could be resolved by a third enzyme such as AluI.

In addition, we constructed a hypothetical RFLP analysis of the 16S-23S ISR-23S rRNA gene contig (Table 3). Whilst such an RFLP analysis could also be used for strain identification, there are occasional anomalies between strains within a $16 \mathrm{Sr}$ subgroup that make such an analysis more problematic. For example, KVE gives different RFLP profiles for all three enzymes tested when compared with blackcurrant reversion disease, despite both strains being in the same 16SrI-C subgroup. Similarly, brinjal little leaf and potato witches'-broom differ with two of the three enzymes tested despite both being in 16SrVI-A, and Crotalaria saltiana phyllody differs from the other 16 SrII-C strains with one of the enzymes tested. These anomalies reflect the high level of variation in the 16-23S ISR as discussed above.

\section{Conclusions}

The inability to culture phytoplasmas has made traditional taxonomy for these organisms impractical, and has led to the development of systems based on genes that can be 
amplified readily from all phytoplasmas and then compared between them. Such systems are therefore based predominantly on the $16 \mathrm{~S}$ rRNA gene, and this led initially to classification into nine primary $16 \mathrm{Sr}$ groups and 14 subgroups (Lee et al., 1993). More recently, analysis of the 16-23S ISR has improved the group resolution (Wang et al., 2003) and further groups have been added as novel strains have been identified, such that, in the most recent classification system, 28 groups (16SrI-16SrXXVIII) have now been recognized (Wei et al., 2007). Based on characteristics such as differences in the 16S rRNA gene of more than $1.2-2.3 \%$, plant host, vector specificity and, in some cases, serological comparisons, some of these groups and subgroups within them have been assigned candidate species names within ' $\mathrm{Ca}$. Phytoplasma' (Seemüller et al., 2002; IRPCM Phytoplasma/Spiroplasma Working Team - Phytoplasma Taxonomy Group, 2004; Firrao et al., 2005). Twenty-three candidate species names have been proposed within ' $\mathrm{Ca}$. Phytoplasma', and novel strains need to share less than $97.5 \%$ 16S rRNA gene sequence similarity to a previously described strain to be assigned to a novel candidate species.

Other genes such as the $r p$ and tuf genes (Marcone et al., 2000; Botti \& Bertaccini, 2003) and the secY gene (Lee et al., 2006) have provided a more detailed subdivision of phytoplasma primary groups such as the 16SrI aster yellows group, and the recent work of Martini et al. (2007) has resulted in the first comprehensive analysis of phytoplasmas between the different groups using coding sequences, those for the $r p$ operon genes $r p l V(r p l 22)$ and $r p s C$ ( $r p s 3)$. In our study, we have identified a new set of universal primers that are capable of amplifying a 482/ $488 \mathrm{bp}$ region of the secA gene from all phytoplasmas tested, which includes phytoplasmas from 12 of the 13 major $16 \mathrm{Sr}$ groups (the exception being 16SrVIII, loofah witches'-broom, for which DNA was not available in this study). Phylogenetic analysis of this DNA, which encodes a 160-162 amino acid region of the SecA protein, confirms and consolidates the previous classification systems but also provides improved resolution between the groups and the subgroups in the form of more discrete and longer branches. In particular, this analysis supports proposals to subdivide the 16SrIV CLY-type diseases into at least three distinct candidate species, and also confirms that the 16SrII group should be subdivided into at least two candidate species within ' $\mathrm{Ca}$. Phytoplasma'. In addition, and based on predicted sizes following restriction enzyme digestion of the secA PCR product, it may be possible to develop these primers and RFLP analysis of the products into a robust system for diagnosing and identifying strains within infected plants.

\section{ACKNOWLEDGEMENTS}

This work was performed as part of a DEFRA Plant Health Fellowship for J. H. The authors would like to thank Dr Phil Jones (Rothamsted Research, UK), Dr Jaraslava Pribylova (Institute of Plant Molecular Biology, Czech Republic), Dr Joseph Nipah (CSIR, Sekondi, Ghana) and Professor Assunta Bertaccini (University of Bologna, Italy) for providing samples. Phytoplasmas were held under DEFRA Plant Health Licence no. PHL 173B/5244.

\section{REFERENCES}

Altschul, S. F., Gush, W., Miller, W., Myers, W. \& Lipman, D. J. (1990). Basic local alignment search tool. J Mol Biol 215, 403-410.

Arnaud, G., Malembic-Maher, S., Salar, P., Bonnet, P., Maixner, M., Marcone, C., Boudon-padieu, E. \& Foissac, X. (2007). Multilocus sequence typing confirms the close genetic interrelatedness of three distinct flavescence dorée phytoplasma strain clusters and group $16 \mathrm{SrV}$ phytoplasmas infecting grapevine and alder in Europe. Appl Environ Microbiol 73, 4001-4010.

Bai, X., Zhang, J., Holford, I. R. \& Hogenhout, S. A. (2004). Comparative genomics identifies genes shared by distantly related insect-transmitted plant pathogenic mollicutes. FEMS Microbiol Lett 235, 249-258.

Bai, X., Zhang, J., Ewing, A., Miller, S. A., Radek, A. J., Shevchenko, D. V., Tsukerman, K., Walunas, T., Lapidus, A. \& other authors (2006). Living with genome instability: the adaptation of phytoplasmas to diverse environments of their insect and plant hosts. J Bacteriol 188, 3682-3696.

Bertaccini, A., Franova, J., Botti, S. \& Tabanelli, D. (2005). Molecular characterization of phytoplasmas in lilies with fasciation in the Czech Republic. FEMS Microbiol Lett 249, 79-85.

Botti, S. \& Bertaccini, A. (2003). Variability and functional role of chromosomal sequences in $16 \mathrm{SrI}-\mathrm{B}$ subgroup phytoplasmas including aster yellows and related strains. J Appl Microbiol 94, 103-110.

De La Rue, S., Padovan, A. \& Gibb, K. (2001). Stylosanthes is a host for several phytoplasmas, one of which shows unique 16S-23S intergenic spacer region heterogeneity. J Phytopathol 149, 613-619.

Deng, S. \& Hiruki, C. (1991). Amplification of $16 \mathrm{~S}$ rRNA genes from culturable and non-culturable mollicutes. J Microbiol Methods 14, 53-61.

Doyle, J. J. \& Doyle, J. L. (1990). Isolation of plant DNA from fresh tissue. Focus 12, 13-15.

Economou, A. (1999). Follow the leader: bacterial protein export through the Sec translocase. Trends Microbiol 7, 315-319.

Firrao, G., Gibb, K. \& Streten, C. (2005). Short taxonomic guide to the genus 'Candidatus phytoplasma'. J Plant Pathol 87, 249-263.

Gundersen, D. E. \& Lee, I.-M. (1996). Ultrasensitive detection of phytoplasmas by nested-PCR assays using two universal primer pairs. Phytopathol Mediterr 35, 144-151.

Harrison, N. A., Myrie, W., Jones, P., Carpio, M. L., Castillo, M., Doyle, M. M. \& Oropeza, C. (2002). 16S rRNA interoperon sequence heterogeneity distinguishes strain populations of the palm lethal yellowing phytoplasma in the Caribbean region. Ann Appl Biol 141, 183-193.

Hodgetts, J., Ball, T., Boonham, N., Mumford, R. \& Dickinson, M. (2007). Use of terminal restriction fragment length polymorphism (TRFLP) for identification of phytoplasmas in plants. Plant Pathol 56, 357-365.

IRPCM Phytoplasma/Spiroplasma Working Team - Phytoplasma Taxonomy Group (2004). 'Candidatus Phytoplasma', a taxon for the wall-less, non-helical prokaryotes that colonize plant phloem and insects. Int J Syst Evol Microbiol 54, 1243-1255.

Jomantiene, R., Zhao, Y. \& Davis, R. E. (2007). Sequence-variable mosaics: composites of recurrent transposition characterizing the genomes of phylogenetically diverse phytoplasmas. DNA Cell Biol 26, $557-564$. 
Kumar, S., Tamura, K. \& Nei, M. (2004). MEGA3: integrated software for molecular evolutionary genetics analysis and sequence alignment. Brief Bioinform 5, 150-163.

Lee, I.-M., Hammond, R. W., Davis, R. E. \& Gundersen, D. E. (1993). Universal amplification and analysis of pathogen 16S rDNA for classification and identification of mycoplasmalike organisms. Phytopathology 83, 834-842.

Lee, I.-M., Davis, R. E. \& Gundersen, D. E. (2000). Phytoplasma: phytopathogenic mollicutes. Annu Rev Microbiol 54, 221-255.

Lee, M. E., Grau, C. R., Lukaesko, L. A. \& Lee, I.-M. (2002). Identification of aster yellows phytoplasmas in soybean in Wisconsin based on RFLP analysis of PCR-amplified products (16S rDNAs). Can J Plant Pathol 24, 125-130.

Lee, I.-M., Zhao, Y. \& Bottner, K. D. (2006). SecY gene sequence analysis for finer differentiation of diverse strains in the aster yellows phytoplasma group. Mol Cell Probes 20, 87-91.

Liefting, L. W., Shaw, M. \& Kirkpatrick, B. C. (2004). Sequence analysis of two plasmids from the phytoplasma beet leafhopper-transmitted virescence agent. Microbiology 150, 1809-1817.

Marcone, C., Lee, I.-M., Davis, R. E., Ragozzino, A. \& Seemüller, E. (2000). Classification of aster yellows-group phytoplasmas based on combined analyses of rRNA and tuf gene sequences. Int J Syst Evol Microbiol 50, 1703-1713.

Martini, M., Lee, I.-M., Bottner, K. D., Zhao, Y., Botti, S., Bertaccini, A., Harrison, N. A., Carraro, L., Marcone, C. \& other authors (2007). Ribosomal protein gene-based phylogeny for finer differentiation and classification of phytoplasmas. Int J Syst Evol Microbiol 57, 2037-2051.

Montano, H. G., Davis, R. E., Dally, E. L., Hogenhout, S., Pimentel, J. P. \& Brioso, P. S. T. (2001). 'Candidatus Phytoplasma brasiliense', a new phytoplasma taxon associated with hibiscus witches'-broom disease. Int J Syst Evol Microbiol 51, 1109-1118.

Mpunami, A. A., Tymon, A., Jones, P. \& Dickinson, M. J. (1999). Genetic diversity in the coconut lethal yellowing disease phytoplasmas of East Africa. Plant Pathol 48, 109-114.
Nipah, J. O., Jones, P. \& Dickinson, M. J. (2007). Detection of lethal yellowing phytoplasma in embryos from coconut palms infected with Cape St Paul wilt disease in Ghana. Plant Pathol 56, 777-784.

Schneider, B., Torres, M. P., Martin, M. P., Schroder, M., Behnke, H. D. \& Seemüller, E. (2005). 'Candidatus Phytoplasma pini', a novel taxon from Pinus silvestris and Pinus halepensis. Int J Syst Evol Microbiol 55, 303-307.

Seemüller, E., Garnier, M. \& Schneider, B. (2002). Mycoplasmas of plants and insects. In Molecular Biology and Pathogenicity of Mycoplasmas, pp. 91-116. Edited by S. Razin \& R. Herrmann. Dordrecht, Netherlands: Kluwer Academic/Plenum.

Shao, J., Jomantiene, R., Dally, E. L., Zhao, Y., Lee, I.-M., Nuss, D. L. \& Davis, R. E. (2006). Phylogeny and characterization of phytoplasmal NusA and use of the nusA gene in detection of group 16SrI strains. $J$ Plant Pathol 88, 193-201.

Smart, C. D., Schneider, B., Blomquist, C. L., Guerra, L. J., Harrison, N. A., Ahrens, U., Lorenz, K.-H., Seemüller, E. \& Kirkpatrick, B. (1996). Phytoplasma-specific PCR primers based on sequence of the 16S-23S rRNA spacer region. Appl Environ Microbiol 62, 2988-2993.

Streten, C. \& Gibb, K. S. (2005). Genetic variation in Candidatus Phytoplasma australiense. Plant Pathol 54, 8-14.

Thompson, J. D., Higgins, D. G. \& Gibson, T. J. (1994). CluSTAL W: improving the sensitivity of progressive multiple sequence alignment through sequence weighting, position-specific gap penalties and weight matrix choice. Nucleic Acids Res 22, 4673-4680.

Wang, K. \& Hiruki, C. (2005). Distinctions between phytoplasmas at the subgroup level detected by heteroduplex mobility assay. Plant Pathol 54, 625-633.

Wang, K., Hiruki, C. \& Yeh, F. (2003). Molecular evolution of phytoplasmas based on polymorphisms in the $16 \mathrm{~S}$ rRNA genes and the 16/23S spacer regions. Proc Jpn Acad Ser B 79B, 155-162.

Wei, W., Davis, R. E., Lee, I.-M. \& Zhao, Y. (2007). Computersimulated RFLP analysis of 16S rRNA genes: identification of ten new phytoplasma groups. Int J Syst Evol Microbiol 57, 18551867. 